\title{
Outcomes of Females with Normal Coronaries on Coronary Angiogram
}

\author{
Mira Govindarajan ${ }^{1}$ \\ ${ }^{1}$ Department of Cardiology, CARE Hospitals, Hyderabad, Telangana, \\ India
}

Indian J Cardiovasc Dis Women-WINCARS 2017;2:63-64

This issue addresses the dilemma of management in women with chest pain and normal coronaries. The protocol for these patients must incorporate probability of future coronary events $^{1}$ and mortality there from. ${ }^{2}$ The economic burden to individual family and community as also the emotional impact must be borne in mind.

Angina in the absence of obstructive coronary artery disease (CAD), sometimes referred to as cardiac syndrome $X$ (CSX), is known to disproportionately affect women. ${ }^{3}$ More than $50 \%$ of women evaluated for angina have nonobstructive disease by cardiac catheterization. ${ }^{4}$

Two hypotheses have existed to explain CSX: the ischemic hypothesis-abnormal coronary microvascular function, and the nonischemic hypothesis describing altered pain perception and myocardial hypersensitivity. A prospective study using intravascular ultrasound (IVUS) and cardiac magnetic resonance imaging (cMRI) in women presenting with acute mycoardial infarction (MI) without obstructive CAD at angiography demonstrated plaque disruption as a frequent finding. ${ }^{5}$

With regard to treatment strategies, $\beta$-blockers have been the mainstay along with other antianginals, angiotensinconverting enzyme (ACE) inhibitors, statins, and lifestyle modifications. However, there is still a paucity of data to define an optimal algorithm for diagnosis and management more so with regard to women. ${ }^{6}$

In a population-based cohort study of 32,856 patients published in 1981, women with angiographically normal coronaries were more than four times more likely to be readmitted to hospital for acute coronary syndrome (ACS)/chest pain within 180 days compared with men. The observed sex difference suggested that traditional diagnostic methods may be inappropriate for women. ${ }^{7}$

The Coronary Artery Surgery Study (CASS) registry ${ }^{8}$ incorporated 25,000 patients undergoing coronary angiography for angina, of whom $39 \%$ of women had normal coronary arteries compared with $11 \%$ of men. Data from 375,886 patients referred for angiography due to stable angina in the American College of Cardiology-National Cardiovascular Data Registry (NCDR) showed that the prevalence of nonobstructive
Address for correspondence Mira Govindarajan, Consultant, Non-Invasive Cardiology, Department of Cardiology, CARE Hospitals, Banjara Hills, Hyderabad, Telangana, India (e-mail: miragdoc@yahoo.co.in).

disease was significantly higher in women (51\%) than in men (32\%).

Higher prevalence in women was again confirmed by the Women's Ischemic Syndrome Evaluation (WISE) study, as per which $62 \%$ of women referred for angiography had nonobstructive CAD.

Our conventional understanding of CAD presupposes that premenopausal women are less likely to suffer from CAD than their age-matched male counterparts. ${ }^{9}$ Though this may be true in a larger context, it becomes pertinent to review the study published by Proudfit et al in Circulation. ${ }^{10}$ This study followed up more than a 1,000 women younger than 50 years for more than 5 years and reported a survival rate of $96.9 \%$. Causes of death were coronary ectasia and sudden cardiac death.

Seven of the 727 women who had less than 30\% luminal narrowing went on to have coronary events whereas 6 of the 324 women who had 30 to $50 \%$ lesions went on to have coronary events. Overall, such cases represented $6.8 \%$ of patients referred for coronary angiography.

Thus the subset of patients presenting with chest pain and angiographically insignificant lesions namely with less than $50 \%$ luminal narrowing presents a challenging situation from the clinical perspective, and protocols for optimal follow-up are yet to be defined.

\section{References}

1 Ahmar W, Lefkovits J. Acute ST elevation myocardial infarction with angiographically normal coronary arteries: causes and outcomes. Int J Cardiol 2008;128(1):131-133

2 Mann DL, Zipes DP, Libby P, Bonow RO. Braunwald's Heart Disease: A Textbook of Cardiovascular Medicine. 10th ed. Saunders; 2014

3 Rosano GM, Collins P, Kaski JC, Lindsay DC, Sarrel PM, Poole-Wilson PA. Syndrome X in women is associated with oestrogen deficiency. Eur Heart J 1995;16(5):610-614

4 Banks K, Lo M, Khera A. Angina in women without obstructive coronary artery disease. Curr Cardiol Rev 2010;6(1):71-81

5 Reynolds HR, Srichai MB, Iqbal SN, et al. Mechanisms of myocardial infarction in women without angiographically obstructive coronary artery disease. Circulation 2011;124(13):1414-1425
DOI https://doi.org/ 10.1055/s-0038-1620320.
Copyright (02017 Women in Cardiology and Related Sciences
License terms

(®) $\Theta \circledast$ 
6 Shaw LJ, Shaw RE, Merz CN, et al; American College of Cardiology-National Cardiovascular Data Registry Investigators. Impact of ethnicity and gender differences on angiographic coronary artery disease prevalence and in-hospital mortality in the American College of Cardiology-National Cardiovascular Data Registry. Circulation 2008;117(14):1787-1801

7 Humphries KH, Pu A, Gao M, Carere RG, Pilote L. Angina with "normal" coronary arteries: sex differences in outcomes. Am Heart J 2008;155(2):375-381

8 Davis KB, Chaitman B, Ryan T, Bittner V, Kennedy JW. Comparison of 15 -year survival for men and women after initial medical or surgical treatment for coronary artery disease: a CASS registry study. Coronary Artery Surgery Study. J Am Coll Cardiol 1995;25(5):1000-1009

9 Hemingway H, Langenberg C, Damant J, Frost C, Pyörälä K, Barrett-Connor E. Prevalence of angina in women versus men: a systematic review and meta-analysis of international variations across 31 countries. Circulation 2008;117(12):1526-1536

10 Proudfit WL, Welch CC, Siqueira C, Morcerf FP, Sheldon WC. Prognosis of 1000 young women studied by coronary angiography. Circulation 1981;64(6):1185-1190 